\title{
MOVIMENTO BRASILEIRO DE ALFABETIZAÇÃO (MOBRAL): AS BALIZAS CURRICULARES, PEDAGÓGICAS E TÉCNICAS
}

\author{
BRAZILIAN LITERACY MOVEMENT (BLM): CURRICULUM, PEDAGOGICAL \\ AND TECHNICAL GOALS
}

\section{Leni Rodrigues Coelho ${ }^{1}$}

RESUMO: Este artigo tem como objetivo analisar os manuais pedagógicos do Movimento Brasileiro de Alfabetização, ressaltando as concepções curriculares, pedagógicas e técnicas adotadas pelo movimento. O MOBRAL, foi criado no governo de Costa e Silva, em is de dezembro de 1967 , pela Lei $\mathrm{n}^{\mathrm{O}} 5.379$ e tinha como objetivo financiar e orientar tecnicamente programa de alfabetização funcional e de educação continuada para adolescentes e adultos. No entanto, foi a partir de 1970, mediante sua desvinculação do Ministério da Educação e vinculação com o Ministério do Planejamento que este se tornou o maior movimento de educação de massa.

Palavras-chave: MOBRAL. Alfabetização. Educação de adultos.

ABSTRACT: This article aims to analyze the pedagogical guides of the Brazilian Literacy Movement, highlighting the curricular, pedagogical and technical concepts adopted by the movement. BLM, was created by President Costa e Silva, on December 15, 1967 by Law No. 5,379 and aimed to finance and technically guide a program of functional literacy and continuing education for adolescents and adults. However, it was in 1970, after its transference from the Ministry of Education and linking to the Ministry of Planning, that it became the largest mass education movement.

Keywords: BLM. Literacy. Adult education.

\section{INTRODUÇÃO}

A educação é considerada um dos setores mais importantes para o desenvolvimento de uma nação, uma vez que o conhecimento propicia o crescimento do país, contribuindo assim para o aumento da renda e da qualidade de vida dos indivíduos. No Brasil, embora tenham ocorrido avanços significativos nesse campo nas últimas décadas, ainda há muito a ser feito, já que os dados do Instituto Brasileiro de Geografia e Estatística mostram que o contingente de indivíduos sem escolaridade no país em 2019, acima de is anos é de

\footnotetext{
${ }^{1}$ Graduada em Pedagogia pelo Centro Universitário de Patos de Minas (UNIPAM), mestra em Educação pela Universidade Federal de Uberlândia (UFU) e doutoranda em Educação pela Universidade do Estado do Rio de Janeiro (UERJ). É professora assistente na Universidade do Estado do Amazonas (UEA), na Escola Normal Superior (ENS). E-mail: lenicoelho@yahoo.com.br
} 
aproximadamente in milhões, cerca de 6,6\%, o que coloca o Brasil em uma situação preocupante acerca dessa questão.

O Brasil, no final dos anos de 1940, vivia um período de redemocratização política e, com o fim do pós-guerra, a Organização das Nações Unidas (ONU) alertava para a urgência de integrar os povos, visando à paz e à democracia. Tais fatos contribuíram para que a educação de adultos se destacasse e fosse motivo de preocupação na educação elementar comum. $O$ surgimento desses fatos definiu a identidade da educação de adultos, tornando-a, desse modo, uma campanha de massa em nível nacional em 1947.

Ao longo das décadas de 1950 e 1960, surgiram várias campanhas e movimentos ligados a educação de adultos, como também buscassem fontes de recursos para sua viabilização. Diante das campanhas criadas e extintas no Brasil, para alfabetizar adultos e diminuir o indice de analfabetismo, o governo de Costa e Silva criou o Movimento Brasileiro de Alfabetização (MOBRAL) em is de dezembro de 1967, pela Lei no 5.379, o qual foi fruto do trabalho de um grupo interministerial.

O MOBRAL tinha o intuito de financiar e orientar tecnicamente programa de alfabetização funcional e de educação continuada para jovens e adultos na faixa etária de is a 35 anos; no entanto, foi a partir de 1970 mediante sua desvinculação do Ministério da Educação para o Ministério do Planejamento que este se tornou o maior movimento de educação de massa. Diante disso, ocorreram mudanças na estrutura interna do projeto, inclusive no setor administrativo e pedagógico, já que sua proposta de educação estava condicionada aos interesses vigentes da época. Assim, suas atividades passaram a ter um planejamento racional, no qual levou-se em conta os propósitos do governo militar que disseminava a ideia de que o país precisava se desenvolver economicamente e por isso, o MOBRAL deveria reproduzir uma política educacional de cunho econômico.

O MOBRAL tinha como meta prioritária erradicar o analfabetismo no país em dez anos de atuação, já que o índice de analfabetismo da população brasileira em 1970 se encontrava elevado, cerca de 33,6\%, o que gerava uma relação desconfortável entre o governo brasileiro e a Organização das Nações Unidas para Educação, Ciência e Cultura (UNESCO), uma vez que esta defendia a ideia de que a educação é de suma importância no que concerne ao desenvolvimento do país. A influência desse órgão se apresentava como um movimento favorável à educação fundamental das massas populares, uma vez que as regiões menos desenvolvidas apresentavam índices elevados acerca do analfabetismo, o que gerava 
preocupação no que se refere à falta de escolarização, pois esta era vista como uma deficiência a ser eliminada.

Para efetivar o MOBRAL foi necessário instalar Comissões Municipais (COMUN) para desenvolver suas atividades. No entanto, o convênio com entidades não governamentais e o apoio de voluntários foram indispensáveis para a implantação de seus programas. $O$ MOBRAL tinha a finalidade de propor uma metodologia inovadora no que tange à alfabetização de adultos e eliminar o analfabetismo em aproximadamente dez anos de atuação. Contudo, demonstrou que o discurso não foi colocado em prática uma vez que, em 1980, ainda havia um percentual significativo de analfabetos no país, ou seja, 25,5\% aproximadamente.

O presente trabalho tem como objetivo realizar uma análise acerca do material didático produzido e adotado pelo MOBRAL, do qual se pretende compreender suas balizas curriculares, pedagógicas e técnicas. Para tanto, foram consultadas os seguintes materiais didáticos: livro de leitura do aluno, o manual de orientação do professor e os livros de módulo complementar. Para fundamentar teoricamente a pesquisa nos aproximamos das discussões de: Beisiegel (1974), Jannuzzi (1979), Paiva (1987), Haddad (1991) e Soares (1995).

\section{Tecnologia educacional e concepção de sujeitos no tecnicismo}

O tecnicismo educacional é uma tendência que surgiu no final dos anos 1960, inspirada na teoria behaviorista da aprendizagem e da abordagem sistêmica do ensino. Nessa perspectiva, o que é valorizado não é o professor, e sim a tecnologia, ou a dimensão técnica do processo didático-pedagógico, uma vez que o professor passa a ser um especialista na aplicação de manuais e sua criatividade fica restrita aos limites da técnica utilizada.

De acordo com Araújo (199I), a técnica de ensino sugere tecnicismo, e este, tecnologia que, por sua vez, está associada ao desenvolvimento, e o tecnicismo à modernização. Dessa forma, a modernização, o desenvolvimento e a tecnologia, não podem ser destacados do para quê e a quem serve. Em termos pedagógicos, é necessário lidar com outros conceitos-chave que compõem também o universo das preocupações com a dimensão técnica do ensino, como por exemplo, técnica, método, metodologia, processo, procedimento, estratégia, tática, recurso, instrumento e atividade, que revestem-se de diferentes concepções de educação.

No decorrer dos anos 1970, o cenário pedagógico assistia a uma expectativa de que os benefícios da tecnificação seriam eficazes no que se refere ao processo de ensino e aprendizagem. Assim, o tecnicismo pedagógico sobreleva as técnicas, os processos e os 
recursos materiais ligados à dinâmica do ensinar e do aprender. Dessa forma, tende-se a enfatizar a autonomia dos recursos técnicos, e a escola tende a ser autônoma no que tange ao processo social, e suas ideias estão associadas à racionalização, à eficiência e à eficácia, ideias essas que permeiam todos os níveis do ensino. Assim, os fundamentos que denominam o tecnicismo, em termos ideológico e cientifico, remontam ao início do século XX, com as obras de Taylor e Fayol, com as teorias sobre administração. Posteriormente, tem-se Norbert Winer com sua obra Cybernetcs, em 1948, Bertalanffy, Bouding e Gagne, com análise de sistema, James Finn, com as concepções de ensino ligadas à utilização de recursos audiovisuais e Skinner, com a psicologia comportamentalista de educação (ARAÚJO, I99I).

$\mathrm{Na}$ década de 1960, assiste-se no Brasil à necessidade de recursos humanos, pois estes devem acompanhar a modernização e está a serviço da industrialização. Nesse contexto, surgiram várias teorizações e o processo pedagógico escolar buscou guiar-se nas teorias psicológicas, sistêmicas, de administração e de comunicação. No entanto, a supervalorização da técnica não é específica do campo educacional, que apenas compartilhou, com os vários setores, os desdobramentos de uma visão tecnocrática. Dessa forma, o tecnicismo é muito maior do que a pedagogia, a técnica pedagógica ou o tecnicismo pedagógico. A partir do final dos anos de 1970, o tecnicismo pedagógico começou a sofrer críticas, e essas são justificadas pela incompatibilidade com a teoria histórico-crítica. No tecnicismo o processo pedagógico era concebido como uma racionalidade objetiva, neutra e eficiente, e podendo ser aplicado em qualquer situação. Assim, acreditava-se que, ao justificar o uso de determinadas técnicas ou recurso, haveria sucesso no ensino-aprendizagem do aluno. A técnica de ensino, ao se tornar o componente principal no processo pedagógico, acabava substituindo, mesmo que simbolicamente, o lugar do professor, já que ela se tornava em destaque, subjugando professores e alunos. (ARAÚJO, i99I).

Diante das análises e críticas feitas por várias dimensões do conhecimento, o tecnicismo pedagógico deixa de ser um paradigma confiável à pratica docente. A partir dos anos de I970, a dimensão técnica no campo pedagógico-escolar é solidificada e, portanto, não ser tecnicista nesse período era constrangedor. Já, no fim da década de I97o e na primeira metade dos anos 1980, começam a ocorrer críticas acerca do tecnicismo e aí ser tecnicista era motivo de constrangimento.

No que tange a tecnologia educacional é definida de forma global como um modo sistemático de preparar, implementar e avaliar o processo da aprendizagem e da instrução em seus objetivos específicos, os quais são baseados nas pesquisas de aprendizagem humana e 
comunicação. No entanto, é necessário empregar recursos humanos e materiais adequados para que a educação se torne mais efetiva. A tecnologia educacional deve ser vista como uma cadeia de esforços que dirige as atividades de inovação em educação. Assim, o conceito de tecnologia educacional dá ênfase aos aspectos qualitativos e, além disso, procura desenvolver tecnologias no intuito de melhorar aquilo que é sugerido. A tecnologia educacional, sob o enfoque sistêmico, interessa-se pelas relações, atuações e interações das diferentes unidades de educação formal e não formal, dentro e fora do sistema educativo (OLIVEIRA e OLIVEIRA, 1974).

Assim, o sistema instrucional é formado por pessoas e recursos materiais e tem por finalidade mudar as capacidades do aluno, ou de um grupo de estudantes através da aprendizagem. Esse sistema deve propiciar mudanças no que se refere, ao conhecimento, às habilidades, às capacidades psicomotoras e intelectuais, às estratégias cognitivas e atitudes. Sistemas de instrução são apenas um dos subsistemas que compõem o sistema maior englobado na definição de tecnologia educacional, no entanto, constitui a espinha dorsal da mesma. Se for aceita a distinção entre instrução e educação, trata-se aqui de problemas relacionados com a tecnologia instrucional e não aos aspectos de tecnologia educacional (OLIVEIRA e OLIVEIRA, 1974).

Na pedagogia tecnicista, o professor ocupa uma posição secundária, uma vez que o elemento principal é o sistema técnico de organização da aula e do curso. O professor é orientado por uma concepção mecanicista e, por isso, seus planejamentos e planos de aula são centrados nos objetivos que são operacionalizados de forma minuciosa. No contexto tecnicista, o uso de recursos tecnológicos e audiovisuais sugere uma modernização do ensino.

No MOBRAL é pregado o discurso de que o alfabetizador é um profissional aberto ao dialógo e que deve procurar discutir assuntos referentes à vida cotidiana, como também, trocar ideias e experiências com seus alunos. De acordo com os manuais do MOBRAL:

Estimulando o debate, o alfabetizador estará permitindo, verdadeiramente, a troca de idéias e opiniões sobre assuntos que são parte da experiência de vida dos alunos. Outro assuntos que surgirem, neste momento, poderão, também, ser debatidos (MOBRAL, 1976, p. 3).

No pregado pelo MOBRAL, o alfabetizador deve ser recrutado no ambiente em que moram os alunos, uma vez que é de suma importância conhecer e valorizar a realidade dos seus alunos. No entanto, percebe-se, através do manual de orientação do professor, que este tem apenas a função de executar os objetivos pré-estabelidos pelo MOBRAL Central. Na metodologia empregada por este movimento, fica evienciada a perspectiva tecnicista, que vê o 
aluno como um indivíduo que reage aos estímulos de forma a corresponder às respostas esperadas pela escola, ou seja, deve ter êxito e avançar de forma progressiva. Os interesses particulares dos alunos não são considerados, uma vez que o objetivo é o de ajustá-lo ao ritmo de aprendizagem oferecido pelo professor. O MOBRAL, embora tenha adotado em seu programa uma vertente tecnicista, pregou o discurso de que a educação de adultos oferecida por ele

[...] não se limita à transmissão de conhecimento, mas, através da participação ativa de todos, objetiva o aproveitamento constante das experiências de vida, oferecendo, assim, oportunidades concretas de expressão, criação e transformação; esta educação, tendo como base a realidade do indivíduo, pretende ainda proporcionar oportunidades de acesso a outras experiências, inclusive as vividas num contexto cultural diferente do seu, favorecendo um enriquecimento cultural (CORRÊA, 1979, p. 279).

De acordo com Corrêa (1979), o MOBRAL propicia aos seus alunos educação para que apliquem de forma prática e imediata, técnicas que os habilitem a ler, escrever e contar, como também capacitá-los para viver melhor em sociedade, já que são induzidos a descobrirem qual é a sua função e o seu papel no tempo e no espaço. No entanto, Jannuzzi (1979) salienta que o MOBRAL concebe a educação como investimento e preparação de mão-de-obra para o mercado de trabalho. Dessa forma, o MOBRAL utilizou um modelo antidialógico, já que não possibilitou a troca de ideias com os profissionais da educação, uma vez que os objetivos a serem atingidos se encontram determinados pelo MOBRAL Central.

\section{Modalidades e métodos de Ensino}

De acordo com Araújo (1991), a apalavra ensino tem sua raiz vinculada ao termo signo, e o verbo latino insignire significa sinalizar, tornar notável, distinguir, analisar. Outro termo que também tem vínculo com o ensino, é instrução. Em latim o verbo instruere, significa erguer, construir, pôr em ordem, formar. Dessa forma, instrução implica uma ação de ordenar, de construir. Ensinar também significa explicar, esclarecer, tornar claro o que é obscuro. Apresentaremos a seguir três modalidades de ensino: o mútuo, o individual e o simultâneo, modalidades estas, adotadas pelo MOBRAL.

O ensino mútuo nasceu no final do século XVIII, devido à ampliação da escolarização, passando a substituir o ensino individual predominante até então. A instrução era desenvolvida pelos próprios alunos e monitores sob a direção de um só professor (ARAÚJO, 199I). 
Quanto ao ensino individual, este implica-se na relação professor/aluno e nessa relação o professor se preocupa em estruturar o ensino em detrimento das necessidades, dos obstáculos, das possibilidades e dificuldades do aluno. Assim, o professor se compromete com o desenvolvimento intelectual e moral do seu aluno (ARAÚJO, I99I).

O ensino simultâneo surgiu na educação escolar ocidental desde meados do século XX. A relação professor/aluno se dá mediante a concepção tradicional, ou seja, cabe ao professor transmitir seus conhecimentos a um grupo de alunos. Neste sentido, o professor tem um papel central na atividade de ensino, no entanto, implica uma ação de caráter coletivo, além de reunir as interações em um grupo de alunos (ARAÚJO, 1991).

Em relação ao MOBRAL, percebe-se que foi priorizado o ensino simultâneo, uma vez que garantia educação a um número maior de pessoas a custos razoáveis. Para Corrêa (1979), O MOBRAL tinha por objetivo oferecer educação às massas populares carentes de instrução do país e, para isso, se fazia necessário um programa em que oferecesse educação em grande escala, ou seja, que atingisse o maior número possível de pessoas no menor tempo possível.

Quanto ao método, Araújo (1991), afirma que este implica um norte ao processo educativo no campo das instituições escolares, e requer planejamento prévio e operacionalização do ensino, já que o caminho a ser percorrido não deveria imprimir esforços inúteis, ou seja, deveria conduzir o educando a aprendizagem. Portanto, o método é visto como um conjunto de processos que se ordenam em vista do ensino e da aprendizagem. Os métodos e as técnicas de ensino estão ligados ao como ensinar, no entanto, isso não é suficiente para se obter bom resultado, uma vez que o como ensinar deve estar ligado ao que se ensina. Os métodos de ensino são classificados como sintéticos (alfabético, fônico e silábico) e analíticos (palavração, sentenciação e global). No entanto, apresentaremos nessa discussão apenas do método sintético, já que o MOBRAL alfabetizou nesta perspectiva.

O método sintético consiste, fundamentalmente, na correspondência entre o oral e o escrito, entre o som e a grafia. Estabelece associação a partir dos elementos mínimos (que são as letras), em um processo que vai das partes ao todo. A ênfase está na análise auditiva para que os sons sejam separados, estabelecendo assim um elo de ligação entre grafema-fonema (letra-som). Este, divide-se em três tipos: alfabético, fônico e silábico.

De acordo com Rizzo (1983), o método alfabético tornou-se universalmente aceito, sendo empregado desde a Grécia e Roma antigas até o final da Idade Média. Nesse método, o aluno aprendia primeiro o nome das letras e suas formas (maiúscula e minúscula) na sequência alfabética. Após a apresentação das letras eram treinadas as sílabas e, posteriormente, estas 
eram apresentadas formando palavras. $\mathrm{O}$ ensino da escrita era paralelo, e dava-se uma ênfase maior à caligrafia das letras. $\mathrm{Na}$ aprendizagem do aluno tinha-se como base a repetição e era enfatizado mais o reconhecimento dos sons da palavra do que a apreensão do significado.

O método fônico passou a ser adotado em substituição ao alfabético na busca de superar a dificuldade existente na diferença entre o nome e o som da letra. Nesse método, os sons das letras são ensinados de forma isolada e, posteriormente, são reunidas em sílabas, palavras e, por último, pequenas frases. É considerado um método lógico, por começar o ensino pelos sons das vogais, a forma da letra e a maneira correta de pronunciá-la. Insiste na repetição das vogais e posteriormente introduz as consoantes em uma determinada ordem préestabelecida, sendo os sons combinados com cada vogal (RIZZO, 1983).

No que se refere ao método silábico, a sílaba é a unidade fonética para o ponto de partida do ensino da leitura. Sua estratégia é de unir consoante e vogal formando a sílaba, e unir as sílabas para compor as palavras. No método silábico é ensinado o nome das vogais e depois o nome de uma consoante, apresentando em seguida as famílias silábicas por ela composta (RIZZO, 1983).

O programa do MOBRAL utilizou o método silábico para alfabetizar os alunos. Para facilitar a aprendizagem da leitura e da escrita o alfabetizador deveria trabalhar com as palavras geradoras, estando atento aos seguintes passos:

Apresentação e exploração do cartaz gerador; estudo da palavra geradora, depreendida do cartaz; decomposição silábica da palavra geradora; estudo das palavras silábicas, com base nas palavras geradoras; formação e estudo de novas palavras; formação e estudo de frases e textos (CORRÊA, 1979, p. I53).

De acordo com Corrêa (1979), a decomposição silábica da palavra geradora, com valorização fonêmica, permitia que o aluno fixasse de imediato, as estruturas silábicas, além disso, possibilitava ao aluno sair de esquemas simples para esquemas mais complexos. Ao decompor a palavra geradora em sílaba, o aluno conheceria as famílias silábicas correspondentes a essa palavra. Após o conhecimento das palavras silábicas era necessário que o alfabetizador levasse o aluno a perceber a função dessas sílabas, para que ele pudesse formar com essas sílabas novas palavras. A partir do estudo das palavras, o aluno seria capaz de formar frases e textos. O manual do alfabetizador salienta a importância de estimular o aluno a se comunicar através da escrita.

[...] O alfabetizador deve sempre estimular o grupo, mostrando que são capazes de escrever as coisas que pensam [...]. Que são capazes, também, de se comunicar com outras pessoas através de cartas, bilhetes, telegramas e outros meios (MOBRAL, 1974, p. 17). 
A seguir, encontram-se palavras geradoras com decomposição silábica por ordem de dificuldades, formação de novas palavras e frase presentes nas lições do livro do aluno do MOBRAL.

Figura I: Palavra geradora e decomposição silábicas. Fonte: MOBRAL (1974).
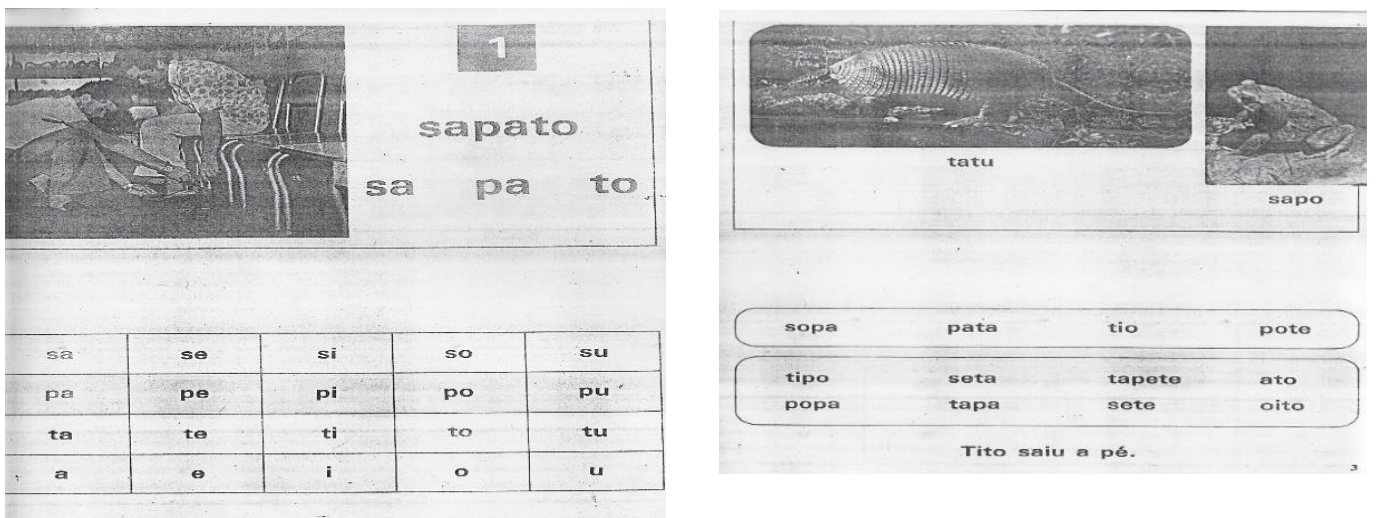

Ao analisar a primeira lição do livro de leitura do aluno do MOBRAL, percebe-se que a palavra geradora é composta pelas famílias silábicas simples, e a lição apresenta uma pequena frase com palavras simples. Tal procedimento é justificado pelo fato de facilitar e estimular a aprendizagem do aluno. Observa-se a seguir que à medida que as discussões vão avançando, as lições apresentam maior grau de dificuldade.

Figura 2: Palavra geradora e decomposição. Fonte: MOBRAL (1974).
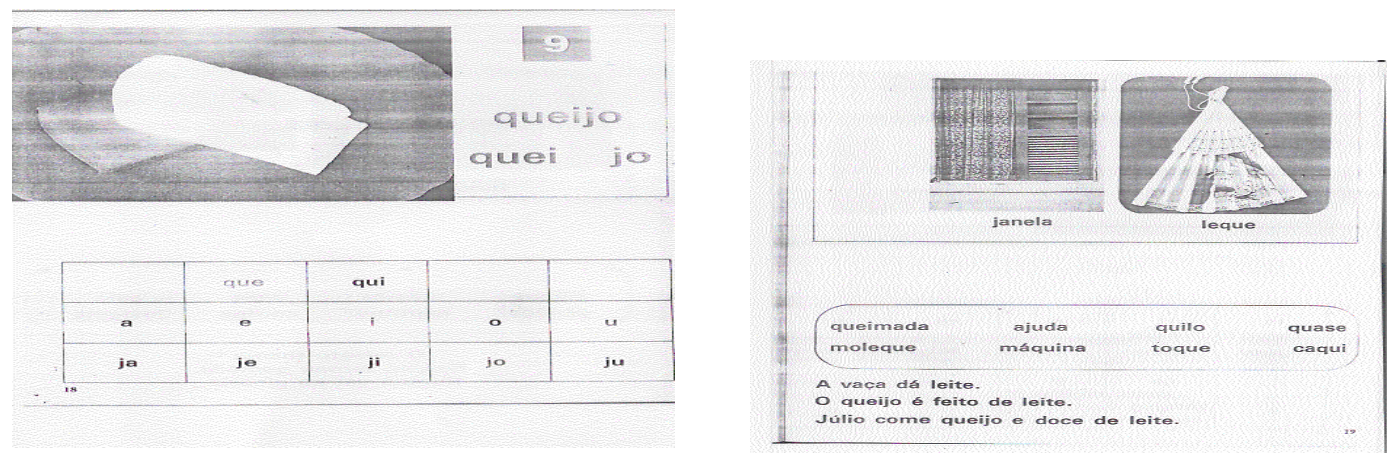

$\mathrm{Na}$ lição de número nove do livro de leitura, verifica-se a existência de palavras geradoras mais complexas, como também se apresentam frases mais longas e com um grau maior de dificuldade. 
Já no livro do professor, A palavra geradora e o aprendizado da leitura e da escrita, traz os passos que o alfabetizador deve seguir. Ao destacar as sílabas, o alfabetizador deve pedir aos alunos que leiam pausadamente a palavra, destacando as sílabas. Por exemplo: a palavra COMI-DA deve ser lida pelo professor de forma que o aluno perceba que esta é composta por três sílabas. Após destacar as sílabas da palavra geradora, o alfabetizador acrescenta as demais sílabas de cada uma das famílias. Na família do CO: CA - CO - CU; depois a família do MI: MA - ME - MI - MO - MU; e finalmente a família do DA: DA - DE - DI - DO - DU.

Diante disso, o alfabetizador formará um quadro de descoberta com as famílias silábicas da palavra geradora, pois é a partir dele que os alunos vão unir as sílabas e descobrir novas palavras. O alfabetizador deve apresentar o quadro de descoberta aos alunos utilizando o quadro de giz e, logo após, desenvolver atividades em que o aluno perceba que as palavras são formadas por sílabas. Isso o levará a descobrir que, se juntarem algumas dessas sílabas poderão formar novas palavras. No livro de leitura do aluno do MOBRAL, percebe-se que, no início, são apresentadas pequenas frases; no entanto, estas vão se tornando mais complexas e formando textos no decorrer do curso. A seguir encontram-se os textos no final do livro de leitura do aluno do MOBRAL.

Figura 3: Lição do Livro de Leitura do Aluno. Fonte: MOBRAL (1974).
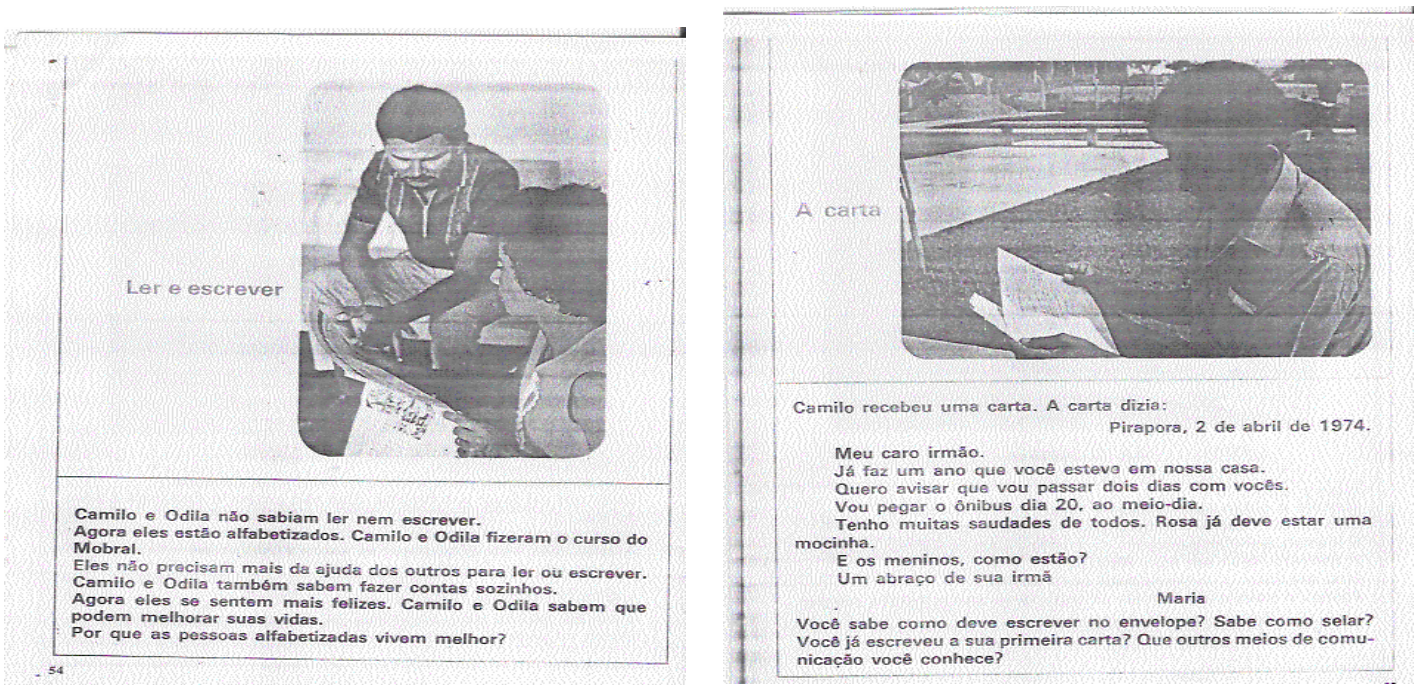

A figura 3 apresentada mostra que a última página do livro de leitura do aluno traz textos com maior complexidade. Percebe-se que os textos abordam assuntos referentes à 
importância da educação, ou seja, discute os benefícios que a educação propicia na vida do ser humano.

\section{Técnicas e Tecnologias Educativas adotadas pelo MOBRAL}

De acordo com Araújo (1991), mesmo que se afirme a unidade e a autonomia da dimensão técnica do ensino, sua razão de ser e sua significação devem ter uma relação mútua com o aluno, o professor, o conteúdo, o ensino, a aprendizagem, a educação, como também com a situação sociocultural dos alunos e os fins que esta se destina. Tais aspectos são elementos que compõem a prática socioeducacional e sua importância não pode ser obscurecida pela dimensão técnica. A técnica de ensino é um componente da racionalidade que procura imprimir o processo pedagógico. $\mathrm{Na}$ busca de realizar tal racionalidade, a técnica tem seu lugar como condição necessária, mas não é suficiente, já que favorece e condiciona o próprio processo pedagógico em sua realização concreta. No entanto, essa racionalidade que se busca para o processo pedagógico não é apenas teórica, mas também prática.

O processo da comunicação entre professor e aluno não deve ser totalmente formal, pois isso pode diluir o processo pedagógico e as técnicas de ensino não devem ser concebidas como algo pronto. As técnicas devem estar a serviço do processo de ensino, ou seja, deve-se destinar ao professor e ao aluno e não estes às técnicas. Como a técnica de ensino não se inscreve formalisticamente, ela não é capaz de realizar tudo sozinha, pois é necessário estar encadeada a outras técnicas e aos elementos componentes do processo pedagógico; sendo assim, a técnica tem um caráter de subordinação aos fins e por isso sua significação é relativa (ARAÚJO, 1991).

De acordo com Corrêa (1979, p. 152), o programa do MOBRAL adotou uma metodologia em que valorizava técnicas de trabalho em grupo, ou seja, as técnicas são direcionadas para o fazer coletivo, o que demonstra trabalho em equipe:

Todo o trabalho metodológico do programa está baseado em técnicas de trabalho em grupo, em ajuda mútua e inserção comunitária. Desenvolvimento pessoal e desenvolvimento comunitário estão intimamente relacionados, um não se fazendo sem o outro.

O discurso pregado por Corrêa (1979), é de que o MOBRAL discute, conjuntamente com os sujeitos envolvidos no movimento, as formas mais viáveis para propiciar educação de qualidade a seus alunos. No entanto, sabe-se que no período do regime militar não houve essa abertura para o diálogo, uma vez que nesse contexto os interesses políticos se sobrelevavam aos objetivos educacionais. 
No que se refere as tecnologias educativas são resultantes do desenvolvimento da eletrônica, da ótica e da informática. Elas propiciaram o reaparecimento do método intuitivo, uma vez que privilegiam a dimensão audiovisual. No entanto, não se pode negar sua associação com o método tradicional. As tecnologias educativas advêm do século XIX, mas é no século $\mathrm{XX}$ que ganham maior amplitude. Tais tecnologias se expressam pela sua materialidade, e essa pode ser maior ou menor em termos de complexidade. (ARAÚJO, I99I).

De acordo com Corrêa (1979, p. 48), o MOBRAL utilizou das novas tecnologias no intuito de oferecer ao professor ferramentas necessárias a uma educação de qualidade, com baixo custo a um número maior de pessoas:

\begin{abstract}
O emprego das novas tecnologias permitirá ultrapassar a fase artesanal em que vive a educação que, aliás, jamais sofreu uma Revolução Tecnológica. Passará, assim, do artesanato para a Era Tecnoetrônica, que garantirá educação a maior número de pessoas, a custo razoáveis; de boa qualidade e centrada no indivíduo. Reservará ao professor, dessa forma, uma tarefa mais rica e importante que a atual, além de elevar seus salários, limitados hoje por questões econômicas óbvias, mas pouco divulgadas (p. 48).
\end{abstract}

\title{
O Material Didático do MOBRAL
}

Com a expansão do Programa de Alfabetização Funcional, tornou-se necessária, a partir de I973, uma reorganização administrativa e uma descentralização operacional das atividades, gerando assim, a necessidade de distribuir um material didático padronizado para todo o país. O MOBRAL distribuiu aos professores e alunos um conjunto didático básico, elaborado de acordo com a metodologia e os princípios do Programa de Educação Integrada (PEI). Esse conjunto era constituído dos seguintes materiais: os livros de leitura, de exercícios de linguagem e de matemática para o aluno, o livro do alfabetizador e um conjunto de cartazes geradores para os professores. Jannuzzi (1979, p. 63) descreve esse material da seguinte forma:

O livro de gravura do professor apresenta um conjunto de vinte cartazes, onde está apresentada a gravura relacionada com a palavra. Estes cartazes são complementados por cartões onde estão impressas só as palavras geradoras, sem a gravura que as representa. Acompanham esse conjunto didático os quadros de descobertas, elaborados com as famílias silábicas de cada palavra geradora. $\mathrm{O}$ aluno por outro lado, recebe a cartilha ou o livro de leitura, onde aparece à gravura da palavra geradora, a sua grafia, as famílias silábicas, algumas palavras formadas pela junção dos fonemas geradores. No final de cada lição há as frases-contexto que mostram palavras formadas com fonemas já estudados e ligados semanticamente a palavra geradora. Textos no final do livro de leitura permitem ao aluno entrar em contato com construções mais complexas. 
Além do material citado anteriormente, os alunos e alfabetizadores recebiam também material didático complementar, sendo esse material constituído de livros de leitura continuada e jornais que serviam de apoio no processo de alfabetização. A seguir, encontram-se explicitados os tipos de materiais didáticos utilizados pelo MOBRAL.

A cartilha foi um tipo de material didático utilizado pelo MOBRAL, embora sua origem no Brasil seja antiga, uma vez que seu surgimento ocorreu no início do século XVI. As cartilhas vinham de Lisboa, Portugal, para a alfabetização na colônia. A primeira cartilha brasileira foi a Cartilha de aprender a ler, de João de Barros, impressa em 1539. No entanto, outras cartilhas foram utilizadas no Brasil: em r850, Antonio Feliciano de Castilho elaborou o Método Castilho, que continha abecedário, silabário e texto de leitura; a cartilha maternal, do poeta João de Deus, em I876; e a Cartilha da infância, de Thomas Galhardo, publicada por volta de I88o. A partir do final do século XIX, foram impressas as primeiras cartilhas de autores brasileiros, mas sua produção só foi se intensificar a partir de 1930 (MENDONÇA e MENDONÇA, 2007).

O uso de cartilhas se dá de forma inadequada, uma vez que abordam apenas a codificação (escrita) e a decodificação (leitura) de sinais, esses fatores ocorrem pelo fato de o alfabetizador não ter em sua formação o embasamento da linguística. Outra crítica colocada a respeito das cartilhas é que não apresentam análise das dificuldades enfrentadas pelos alunos ao aprenderem a ler e a escrever. As cartilhas são planejadas para quem não apresenta dificuldades, seguindo as lições sem interrupção, e quando o objetivo não é alcançado, se recomeça tudo novo, ou seja, desde a primeira lição. As cartilhas apresentam também um tempo determinado e curto para que o aluno aprenda a ler, não levam em conta os obstáculos enfrentados pelos alunos (MENDONÇA e MENDONÇA, 2007).

Quanto ao MOBRAL, Corrêa (1979, p. 50) afirma que as cartilhas adotadas são compostas de palavras de curso universal em todo o país, cabendo ao alfabetizador a responsabilidade de enfatizar a tonalidade local do discurso educativo:

[...] nossas cartilhas são construídas com palavras corriqueiras do universo lingüístico brasileiro, ilustradas por cartazes sugestivos, com imagens 
familiares a todos os alunos. Palavras que se prestam á discussão de seus grandes problemas, pois são retiradas das necessidades básicas do homem (comida, remédio, tijolo, família, etc.), mas que não contêm uma carga de ódio nem são desnecessariamente mórbidas (fome, doença, etc.).

Diante disso, percebe-se que o MOBRAL prega o discurso ideológico de que preocupa com a realidade do aluno, embora seu material seja distribuído de forma padronizada para todo o país. Segundo Jannuzzi (1979), o material didático do MOBRAL foi confeccionado por uma equipe central, sendo utilizado em todo o Brasil. Esse material foi elaborado de modo que oferecesse oportunidade ao aluno de caminhar no processo de alfabetização dentro das técnicas analítico-sintética.

De acordo com Corrêa (1979), o livro de leitura adotado pelo MOBRAL objetivava não apenas desenvolver as habilidades de ler, escrever e contar, como também pensar e discutir assuntos referentes a problemas enfrentados pela sociedade, buscando soluções para resolvê-los. Acreditava-se que tal material favorecia a integração do aluno na comunidade, em virtude dos assuntos que aborda. O livro de leitura do aluno não tinha apenas a intenção de fixar as palavras estudadas, mas também incutir no aluno o hábito da leitura de pequenos textos. $O$ manual do professor do MOBRAL salientava a importância da utilização do livro de leitura do aluno:

Os livros de leitura podem ser utilizados em classe, desde o início do programa, isto porque, alguns de seus assuntos enriquecem idéias básicas que são geradas pelo trabalho com os cartazes e as palavras geradoras. Desse modo, a utilização dos livros de leitura, além de desenvolver no aluno as habilidades de ler, de fazer com que ele se habitue a entender informações escritas, ainda permite aprender coisas que poderá pôr em prática para seu benefício (MOBRAL, i976, p.3).

Outra justificativa dada pelos dirigentes do MOBRAL em relação ao livro de leitura é de que o aluno deve ter contato com o livro não apenas em sala de aula, pois este, ao levá-lo para casa tem a oportunidade de envolver outras pessoas que vivem com ele. Essas pessoas ao lerem os livros aprendem coisas que o ajudam a resolver problemas do seu cotidiano, já que tais livros abordam assuntos não só de interesse do aluno, mas também de toda a comunidade.

No que diz respeito ao cartaz, Carvalho (1979), afirma que este é um recurso didático que apela para o sentido da visão como fonte de experiência. É importante destacar a importância de levar em consideração o tema ou a mensagem que se 
pretende comunicar, como também apresentar as ilustrações, os textos e a estética coerentes com os objetivos a serem alcançados. Esse recurso se bem utilizado é considerado valioso no que tange ao trabalho didático do professor.

Esse recurso foi utilizado pelo MOBRAL com o intuito de auxiliar o trabalho do professor em sala de aula. De acordo com Jannuzzi (1979, p. 64), o cartaz gerador tem o seguinte objetivo:

[...] favorecer a troca de experiências, o enriquecimento informativo e o uso freqüente da palavra geradora. Deve ser discutido até que a palavra geradora seja decodificada, isto é, aprendida na sua significação. Então o que se faz neste primeiro momento é analisar o cartaz gerador, com o objetivo de decodificar a palavra geradora.

Para Corrêa (1979), o cartaz gerador deve ser apresentado aos alunos do MOBRAL nas primeiras aulas de cada palavra geradora, pois este ajuda o professor na apresentação e exploração dessa palavra que se encontra juntamente com a imagem no cartaz despertando, assim, interesse de participação dos alunos. Nesse sentido, o alfabetizador tem um papel importante no que tange à comunicação e à expressão dos pensamentos e experiências de seus alunos, uma vez que essa técnica gera o debate, que é sistematizado no final da aula pelo professor. Encontra-se na obra intitulada Leitura Continuada e as Habilidades de Leitura, publicada pelo MOBRAL e direcionada ao professor, a justificativa de se explorar o cartaz gerador:

Quando o aluno fala ou quando está ouvindo os colegas falarem a respeito de assuntos de um cartaz gerador, ele já está se preparando para entender a palavra geradora que será apresentada após o debate. No momento em que a palavra é lançada, ele começa a aprender a ler essa palavra. Isso porque ela não surgiu ao acaso, foi gerada numa conversa, numa discussão onde ele participou ativamente. Então essa palavra já diz alguma coisa para ele. Tem um significado para sua vida. Não são apenas letras formando sílabas, sem sentido (MOBRAL, 1976, p. 6).

Dessa forma, percebe-se que o cartaz gerador se apresenta como sendo uma ferramenta de suma importância para o professor do MOBRAL no que tange aos recursos disponibilizados em sala de aula.

No que se refere ao manual de orientação do professor, Mendonça e Mendonça (2007) afirmam que esse surgiu por volta de 1944, com a função de orientar o professor quanto ao correto uso do material didático-pedagógico. 
No que se refere ao manual do professor do MOBRAL, percebe-se que orienta e direciona os objetivos terminais que o professor deve atingir com seus alunos. Nesse sentido, o prefácio do manual do professor revela quais são os objetivos pretendidos pelo MOBRAL, e a partir disso, o trabalho do professor deve:

[...] voltar-se para a consecução de tais objetivos, sendo o aluno considerado apto, na medida em que demonstrar o domínio de conhecimentos/habilidades/atitudes sob a forma de objetivos terminais em cada área de estudo. Pretendemos com esta publicação ajudá-lo a selecionar as atividades de ensino e facilitar o processo instrucional de sistematizar e ordenar aptidões e conhecimentos que o aluno adquiriu com a vida (MOBRAL, p. 1978).

No manual do professor do MOBRAL, os objetivos a serem atingidos vêm explicitados de forma separada através da área de conhecimento. Nesse sentido, o MOBRAL priorizou as seguintes áreas: comunicação e expressão, matemática, integração social, ciências físicas e biológicas e educação para o trabalho. $\mathrm{Na}$ área de comunicação e expressão os objetivos terminais que o professor deve atingir com seus alunos em sala de aula são:

Identificar as várias formas de linguagem como instrumento de expressão e comunicação, utilizando-as; demonstrar o domínio da expressão oral e escrita, traduzindo ideias, pensamentos e sentimentos em frases organizadas; demonstrar o domínio da leitura, aplicando as habilidades de compreensão do material lido a textos informativos e recreativos; identificar o sentido das palavras, empregando-as de acordo com o contexto; demonstrar a habilidade de pronunciar e representar por escrito as palavras da língua portuguesa, apontando a diversidade regional da fala e a unidade nacional da ortografia; demonstrar o domínio da entonação e pontuação e demonstrar o domínio da estrutura da língua, identificando os seus elementos e relações (MOBRAL, I978, p. 4).

O ensino da matemática oferecido pelo MOBRAL traz no manual do professor os seguintes objetivos:

Demonstrar domínio da leitura e escrita de números; demonstrar domínio na realização de operações com números naturais, aplicando as regras operatórias em situações de vida prática; demonstrar domínio no uso das propriedades dos números naturais e suas aplicações; demonstrar domínio no uso dos números racionais; identificar as unidades de medidas, empregando-as em situações de vida prática (MOBRAL, 1978, p. 2I).

De acordo com Corrêa (1979), no MOBRAL, o ensino de matemática é paralelo ao da leitura e escrita, e o professor deve ter como ponto de partida o conhecimento prévio do aluno, para depois sistematizá-los e ampliá-los. 
Na disciplina de integração social o manual do professor do MOBRAL objetiva levar seus alunos a conhecer os direitos e deveres das instituições: escola, igreja e família, uma vez que acredita na ação conjunta de tais instituições no que se refere ao bem estar do indivíduo e da comunidade. Nessa área de conhecimento o MOBRAL oferece conteúdos relacionados às disciplinas conhecidas atualmente como geografia e história. Os objetivos propostos no manual do professor demonstram a preocupação em levar o aluno a assimilar os conhecimentos básicos dessa disciplina, como também conhecer seus direitos e deveres perante a sociedade.

Em ciências físicas e biológicas, percebe-se que seus objetivos estão mais direcionados para a vida no campo, uma vez que enfatizam a importância de utilizar corretamente as riquezas e produtos gerados através do solo e subsolo.

No que se refere à educação para o trabalho, o MOBRAL se propõe levar o aluno a perceber a importância do trabalho humano enquanto meio de promoção pessoal, propiciando-lhe conhecimentos acerca dos direitos e deveres do trabalhador. Objetiva também incutir nos alunos a mentalidade de que a aprendizagem e o aperfeiçoamento profissional devem ser contínuos, uma vez que favorecem o desenvolvimento econômico e social da sociedade. Segundo Corrêa (1979, p. 307):

\footnotetext{
Pretende-se com este programa, na verdade, não uma qualificação profissional no seu sentido mais formal, e sim uma disseminação de técnicas e atitudes para o trabalho que permitam ao aluno uma iniciação profissional. Evidencia-se, geralmente, a preocupação com a elevação do nível de cultura técnica do povo brasileiro.
}

O programa do MOBRAL tem equivalência com as quatro primeiras séries do ensino fundamental. Tendo em vista os objetivos terminais estabelecidos pelo MOBRAL Central, percebe-se que este propunha aos seus alunos os conhecimentos básicos da aprendizagem, o que lhes possibilitaria continuar os estudos no sistema regular de ensino após o término do curso. No entanto, sabe-se que o MOBRAL foi fixado com uma duração de 5 meses, com 2 horas diárias de aula, tempo considerado curto pelos alfabetizadores, uma vez que tais objetivos requeriam um tempo maior.

De acordo com Corrêa (1979), o roteiro de orientação do alfabetizador é considerado como um meio de capacitação, uma vez que apresenta a teorização sobre 
educação de adultos, juntamente com os objetivos a serem seguidos pelo programa em uma linguagem simples e acessível.

Outro recurso didático muito utilizado em sala de aula é o quadro-negro, ou quadro-de-giz. Esse recurso é considerado um dos meios auxiliares de ensino mais empregado, e sua utilização em sala de aula é feito a mais de um século. Apesar de seu uso ter sido difundido universalmente, grande parte dos professores não sabem retirar dele o máximo proveito, uma vez que desconhecem os fins a que se presta. Esse recurso é considerado barato e econômico, por isso da sua acessibilidade. O quadro-de-giz pode ser confeccionado de ardósia e, na maioria das escolas é geralmente pintado de verde e usa-se giz branco, embora pesquisas revelem que o ideal seja utilizar quadro cor de marfim e giz azul escuro (CARVALHO, 1979).

O quadro-negro, ou quadro-de-giz, foi um recurso bastante utilizado pelo alfabetizador do MOBRAL, uma vez que os conteúdos são apresentados de forma expositiva aos alunos, o que o torna indispensável em sala de aula.

O MOBRAL adotou também como recurso para facilitar à aprendizagem do aluno o quadro de descobertas, em que apresentava as palavras geradoras. De acordo com Corrêa (1979), tais palavras foram selecionadas pelo MOBRAL a partir das necessidades básicas do ser humano, o que garante o interesse e envolvimento do aluno. Essas palavras têm uso universal em todas as regiões do país. Além disso, o programa teve a preocupação com a pertinência semântica em relação ao mundo físico e psíquico de seus alunos, uma vez que levava em conta o contexto social e profissional do aluno. No manual do professor o uso da palavra geradora tem a seguinte justificativa:

\footnotetext{
Ao trabalhar com a palavra geradora, o alfabetizador deve auxiliar o aluno nas possíveis dificuldades para que este tenha a oportunidade de aprender a ler e escrever, expressar suas idéias e aumentar os conhecimentos que podem ser úteis em sua vida (MOBRAL, 1976, p. 18).
}

No material didático do MOBRAL, as palavras geradoras apareciam em ordem crescente de dificuldade, partindo das mais simples para as mais complexas, pois acreditava-se que isso facilitava e estimulava a aprendizagem do aluno. As palavras geradoras são trabalhadas pelo alfabetizador da seguinte forma: no primeiro momento, o alfabetizador apresenta aos alunos as palavras consideradas como necessidades 
básicas e sua exploração se dá através do cartaz gerador e do significado da palavra. À medida que o aluno desenvolve sua capacidade de leitura, o alfabetizador vai apresentando as palavras geradoras, partindo das formas mais simples para as mais complexas.

De acordo com Corrêa (1979, p. 49), o MOBRAL ofereceu aos seus alunos uma educação conscientizadora, uma vez que propiciou a eles uma concepção de homem e de sociedade pautada em princípios democráticos, além de oferecer qualidade de vida à população carente:

Nestes quase sete anos de trabalho intenso, jamais deixamos de nos indagar se a Instituição estava realmente cumprindo sua missão de contribuir para o desenvolvimento do país e para a melhoria da qualidade de vida da população brasileira mais carente. Nunca, também, sentimos qualquer dúvida acerca da resposta, pois o MOBRAL, mesmo analisado do ponto de vista mais severamente crítico, é uma realização sem precedentes na área social, pelo seu dinamismo, pelo engajamento dos que nele trabalham, pela eficiência e eficácia de sua atuação.

Embora o presidente do MOBRAL Central, Arlindo Lopes Corrêa, pregasse o discurso de que o MOBRAL adotou um material didático-pedagógico com base democrática, percebe-se que esse discurso não condiz com a prática, uma vez que sabese que o MOBRAL foi desenvolvido no período do regime militar, período esse em que a participação popular foi suprimida. A cerca dessa questão, Jannuzzi (1979, p. 66), salienta que:

\footnotetext{
Esse método antidialógico é adequado as finalidades de trazer todos ao 'está sendo' escolhido, uma vez que não permite jamais questioná-lo, que não o analisa, que não parte da realidade do universo vocabular que exprime o modo de ver o mundo segundo o alfabetizando [...]. Não tem interesse de captar o pensamento-linguagem do povo, mas dar o significado que existe, que foi previamente determinado. Os momentos de horizontalidade que permite, também são adequados, porque feitos ao nível da ação são meios de concretizar mais facilmente os objetivos prefixados.
}

Portanto, o material didático-pedagógico adotado pelo MOBRAL traz uma concepção de educação pautada em bases não democráticas, já que não deu a oportunidade de participação dos profissionais da educação em seu projeto educacional. Ao analisar o material didático, verifica-se, principalmente no manual de orientação do professor, que os objetivos terminais estão pré-estabelecidos, cabendo ao alfabetizador apenas a função de colocá-los em prática, pois tal manual tem o objetivo 
de instruir e dirigir o trabalho docente. Diante dos objetivos terminais, o alfabetizador deve seguir as dicas pré-determinadas a fim de que não haja erro, ou seja, se o professor seguir os caminhos determinados pelos dirigentes do MOBRAL, certamente os objetivos estabelecidos serão atingidos.

Dessa forma, o material didático-pedagógico do MOBRAL revela a preocupação em oferecer ao seu aluno apenas as habilidades básicas da leitura e escrita, embora pregasse o discurso de que propiciava ao aluno uma educação capaz de transformar a situação sócioeconômica dos alunos.

Assim, fica explícito que o material oferecido pelo MOBRAL traz o discurso ideológico de que propiciva a elevação do nível sócioeconômico dos alfabetizandos, uma vez que estes têm a oportunidade de adquirir novos conhecimentos, o que lhes possibilitava melhores condições de vida. O MOBRAL salienta também a responsabilidade individual no que tange ao êxito ou fracasso pessoal, pois tal estratégia diminui os riscos de uma possível contestação no que diz respeito à efetivação desse discurso. No entanto, sabe-se que esta é uma visão parcial da realidade, já que a simples alfabetização pouco influenciará na vida dos indivíduos.

\section{Referências}

ARAUJO, José Carlos Souza. Para uma análise das representações sobre as técnicas de ensino. In.: VEIGA, Ilma Passos Alencastro (org.). Técnicas de ensino: Por que não? Campinas, SP: Papirus, I991.

Do quadro-negro à lousa virtual: técnica, tecnologia e tecnicismo. In.: VEIGA, Ilma Passos Alencastro (org.). Técnicas de ensino: Novos tempos, novas configurações. Campinas, SP: Papirus, 2006.

CORRÊA, Arlindo Lopes. Educação de Massa e Ação Comunitária. Rio de Janeiro: MOBRAL AGGS, 1979 .

CARVALHO, Irene Mello. O processo Didático. 3. ed. Rio de Janeiro: FGV, 1979.

FÁVERO, Osmar. Lições da História: os avançõs de sessenta anos e a relação com as políticas de negação de direitos que alimentam as condições do analfabetismo no Brasil. In: OLIVEIRA, Inês Barbosa; PAIVA, Jane. (Orgs.) Educação de Jovens e Adultos. Rio de Janeiro: DP\&A, 2004.

JANNUZZI, Gilberta Martino. Confronto Pedagógico: Paulo Freire e MOBRAL. São Paulo: Cortez \& Moraes, 1979 . 
MENDONÇA, Nádia Jaime: MOBRAL: do discurso a realidade. Revista Brasileira de Estudos Pedagógicos. Instituto Nacional de Estudos Pedagógicos. Rio de Janeiro: v. I, n. I, p. 576-592, jul. 1984 .

MENDONÇA, Onaide Schwartz; MENDONÇA, Olympio Correa. Alfabetização: método sociolinguístico: consciência social, silábica e alfabética em Paulo Freire. São Paulo: Cortez, 2007 .

MOBRAL. Fundação Movimento Brasileiro de Alfabetização. Ministério da Educação e Cultura. Conjunto de Alfabetização: Leitura. Rio de Janeiro: Primor educacional, 1974.

MOBRAL. Fundação Movimento Brasileiro de Alfabetização. SUSUG. Leitura continuada e as habilidades de leitura. Rio de Janeiro: MOBRAL, 1976.

MOBRAL. Fundação Movimento Brasileiro de Alfabetização. SUSUG. A palavra geradora e o aprendizado leitura e da escrita. Rio de Janeiro: MOBRAL, 1976.

MOBRAL. Fundação Movimento Brasileiro de Alfabetização. Ministério da Educação e Cultura. Objetivos terminais: programa de educação integrada. Rio de Janeiro: MOBRAL/MEC. DSU, 1978.

OLIVEIRA, João Batista Araujo; OLIVEIRA, Mariza Rocha. Tecnologia instrucional: um enfoque sistémico. São Paulo, Pioneira, 1974.

PAIVA, Vanilda Pereira. Educação Popular e Educação de Adultos. 5. ed. São Paulo: Loyola, 1987.

RIZZO, Gilda Meneses. Os diversos métodos de ensino da leitura e da escrita: estudo comparativo. 3. ed. Rio de Janeiro: América, 1983. 